\title{
Evaluating the effects of climate change on the water resources for the city of Birmingham, UK.
}

\section{Andrew J. Warren \& lan P Holman}

Natural Resource Department, Cranfield University, Bedfordshire, MK43 OAL, UK.

\section{Keywords}

Elan valley, Hydrologically Effective Rainfall, Modelling, Reservoir, UKCP09, Water Supply, Weather Generator, Adaptation.

\section{Correspondence}

Ian Holman, Natural Resource Department, Cranfield University, Cranfield

Bedfordshire, MK43 OAL, UK

Email: i.holman@cranfield.ac.uk

\begin{abstract}
Climate change is expected to affect precipitation patterns and may therefore impact upon water resource availability. The city of Birmingham in central England receives its public water supply from a catchment in the Elan valley, mid Wales. Baseline and future climate projections generated from a stochastic weather generator within the United Kingdom Climate Projections 2009 and a daily soil water balance model (WaSim) were used to determine the potential impacts of climate change on Hydrologically Effective Rainfall (HER). Annual HER is likely to decrease from baseline conditions (> 90\% likelihood that HER will be reduced), with more frequent and persistent very dry spells and increasing seasonality. It is concluded that climate change will put additional stress on water resources for the city of Birmingham so that, coupled with expected increases in demand, adaptation measures to increase supply and / or reduce demand are likely to be needed.
\end{abstract}

\section{Introduction}


The evidence to suggest that global climate is changing is unequivocal with findings from the Intergovernmental Panel on Climate Change (IPCC) attributing $>90 \%$ confidence that this is due to anthropogenic greenhouse gas emissions (IPCC, 2007). Global temperatures have risen by nearly $0.8^{\circ} \mathrm{C}$ since the late $19^{\text {th }}$ century, and projections suggest that global temperature increases of between $1.1-6.4^{\circ} \mathrm{C}$ are likely by 2100 , dependent on greenhouse gas emissions (IPCC, 2007). Climate patterns are shifting with increasing frequency of intense rainfall projected across much of the UK, whilst summers have been generally getting warmer and drier (Fowler \& Ekstrom, 2009; Osborn \& Hulme, 2002). Such changes have the potential to reduce water resources, putting additional stress on the environment and impacting on the quality and quantity of supplies available for society (Bates et al. 2008). Reservoirs will be impacted in terms of operation and their capacity may need to be increased to ensure sufficient water supplies are available to meet demand during deficit periods (Jones, 1999). The scale of this potential impact is already being felt across the UK with droughts in June 2010 leading to hose pipe bans affecting 6.5 million customers in the North East of England (CEH, 2010).

The city of Birmingham in central England is the UK's second largest city, with a population in excess of 1 million. Birmingham receives all of its potable water needs from the Elan valley reservoirs, with around $320 \mathrm{Ml} / \mathrm{d}$ of water supplied in a normal demand year (STW, 2010). The effect of climate change on this important catchment is uncertain and there is therefore concern over the future reliability of water supplies for Birmingham. This case study aims to assess the potential effects of climate change on Hydrologically Effective Rainfall (HER) in the Elan valley under a range of emissions scenarios and time steps using the UKCP09 stochastic weather generator. HER represents the precipitation-derived water that is able to flow to the reservoir through surface water and groundwater pathways. Water companies need to respond to the challenges of climate change and measures to adapt to climate change are discussed in light of the findings of this study. Although this study focuses on a particular UK catchment, the methodological insights will have wider significance. 


\section{Study Area}

The Elan valley catchment, with an area of $184 \mathrm{~km}^{2}$ and an elevation of around 400$550 \mathrm{~m}$ above sea level, is located between $-3^{\circ} 44^{\prime} 24^{\prime \prime} \mathrm{E} \_52^{\circ} 20^{\prime} 24^{\prime \prime} \mathrm{N}$ and $3^{\circ} 34^{\prime} 12^{\prime \prime} \mathrm{E} \_52^{\circ} 13^{\prime} 48^{\prime \prime} \mathrm{N}$ in mid Wales, UK (Figure 1). The Elan valley reservoirs were built between 1893 and 1904 for the Corporation of Birmingham in order to provide adequate water supplies to its rapidly increasing workforce (CPAT, 2010a). An aqueduct was built to transport the water by gravity along the 73 miles to Frankley water treatment works near Birmingham where it is still processed today. A severe drought occurred in 1937 which led to the construction of the Claerwen reservoir which opened in 1952, increasing the capacity of the Elan valley reservoirs to around 100 billion litres (Marsh \& Hannaford, 2008). The catchment is underlain by Silurian and Ordovician sedimentary rocks with blanket basin peat in the uplands and Palaeozoic slate, mudstone and siltstone throughout the remainder (Rudeforth et al. 1984). The catchment mainly consists of natural grassland (Figure 1). It rains on average 235 days of the year contributing to an average annual rainfall of $1841 \mathrm{~mm}$ (Marsh \& Hannaford 2008).

[Figure 1 about here]

\section{Methodology}

In order to assess the effects of climate change upon water resources in the Elan valley, a stochastic weather generator was first used to generate multiple realisations of daily time series of precipitation and potential evapotranspiration for baseline and future climate scenarios. Secondly, a soil water balance model (WaSim - Hess \& Counsell, 2000) was used to simulate daily hydrologically effective rainfall for the reservoirs' catchment for the baseline and each of these future scenarios.

\section{Climate change scenarios}


The United Kingdom Climate Projections 2009 or UKCP09 (Jenkins et al., 2009) were developed on behalf of the United Kingdom Climate Impacts Programme (UKCIP). A multi model ensemble from 12 different climate models combined with a perturbed physics ensemble using the HadSM3 Global Climate Model (GCM) in a Bayesian statistical framework was used to generate probabilistic climate projections at a $25 \mathrm{~km}$ scale resolution (Murphy et al. 2009). The climate scenarios use a low, medium and high emissions scenario corresponding with IPCC emission scenarios B1, A1B and A1F1 respectively (Nakicenovic \& Swart, 2000). Baseline and seven future overlapping 30 year time slices are available - the 2020's (2010-2039), 2030's (2020-2049), 2040's (2030-2059), 2050's (2040-2069), 2060's (2050-2079), 2070's (2060-2089) and 2080's (2070-2099).

A weather generator (Jones et al. 2009) provides finer spatial ( $5 \mathrm{~km}$ resolution) and temporal (daily or hourly time step) detail. The WG uses two stochastic models in series to generate internally consistent daily weather variables, the first generating rainfall data and the second generating other weather variables such as temperature, humidity and Potential evapotranspiration (ETp) from this primary variable using inter variable mathematical / statistical relationships (Kilsby et al. 2007). ETp is calculated using the FAO modified Penman Monteith method (Doorenbos \& Pruitt, 1977).

The weather generator was applied to a group of $5 \mathrm{~km} \times 5 \mathrm{~km}$ grids representing the Elan catchment, as it does not allow for spatio-temporal correlation. One hundred randomly generated runs provided equally probable and statistically credible representations of weather variables for baseline conditions and for each combination of emissions scenarios and timeslice. Watts et al. (2004) states that there is similar variability across 100 weather generator runs as there are with 1000 runs.

\section{WaSim soil water balance model}

\section{Model description}


WaSim is a one dimensional daily soil water balance model that simulates inputs (Precipitation), outputs (actual evapo-transpiration, surface runoff, potential recharge and drainage) and changes in soil water storage in response to weather (Hess \& Counsell, 2000). WaSim was chosen due to its flexibility, data availability and demonstrated value as a research tool in hydrological studies (eg. Fasinmirin et al. 2008; Holman et al. 2009; Hess et al. 2010).

The soil is divided into up to 5 compartments (Figure 2). Water moves from upper compartments to lower compartments when the soil layer exceeds field capacity and any water draining out of the lowest layer of a freely drained soil is taken as potential recharge. For seasonally waterlogged soils, drain flow occurs when the water table is above the height of the ditches or drain and is a function of the mid drain water table height (after Youngs et al., 1989). Surface runoff comprises the infiltration-excess runoff (estimated using the widely recognised SCS curve number method of Conservation Engineering Division, 1986) and runoff due to saturated soil. Any precipitation that does not run off is assumed to infiltrate.

Actual evapotranspiration is taken as the area-weighted average of soil evaporation (estimated using the method of Ritchie, 1972) and plant transpiration. Plant transpiration is assumed to occur at a rate proportional to the reference evapotranspiration (Allen et al. 1998) depending on the plant type and soil water content, but does not take into account the effect of raised atmospheric $\mathrm{CO}_{2}$ concentrations (Gedney et al. 2006). It occurs at the potential rate whilst the root zone soil water content is between field capacity (here defined as the soil water content at a suction of $5 \mathrm{kPa}$ ) and the limit of easily available water (at $200 \mathrm{kPa}$ ), and under restricted water supply decreases linearly to zero at permanent wilting point (1500 kPa) (Brisson, 1998). For soil water contents above field capacity, it decreases linearly to zero when the root zone soil water content reaches saturation $(0 \mathrm{kPa})$. 
Hydrologically Effective Rainfall (HER) is taken as the sum of potential recharge and runoff in freely draining soils and of drainage and runoff in slowly permeable, seasonally waterlogged soils.

[Figure 2 about here]

\section{WaSim model set-up}

WaSim requires data on the soil, land cover, drainage and weather. The dominant soils in the catchment (from Rudeforth at al. 1984) are blanket peat (Crowdy series - 39\% of the catchment), seasonally waterlogged clay loam soils over impermeable rocks (Hafren series-39\%) and freely draining clay loams (Manod series-18\%) with the remaining $4 \%$ of the catchment consisting of the reservoirs. These are within Soil Hydrological Groups D (Crowdy) and C (Hafren and Manod), and are assumed to be in Fair soil condition (Conservation Engineering Division, 1986). Volumetric water contents at suctions of $0,5,200$ and $1500 \mathrm{kPa}$ and hydraulic conductivity are given in Table 1.

Permanent grass was represented with a crop coefficient (representing the ratio of crop potential evapotranspiration to reference potential evapotranspiration) of 1 and a rooting depth of $0.5 \mathrm{~m}$.

For each of these 21 climate scenarios ( 3 emissions scenarios for each of the 7 different time slices) WaSim was run for each combination of soils (3) and weather files (100). The HER outputs for each soil type were then area-weighted, with the reservoir effective rainfall calculated as precipitation minus evaporation, taken as 1.2 times ETp (Penman, 1950).

\section{Results}

\section{Weather Variables}


Average annual rainfall (AAR) in the catchment derived using the UKCP09 weather generator is projected to increase from baseline $(1876 \mathrm{~mm})$ over the 7 time periods for low, medium and high emission, with the 2080's under high emissions having a median AAR across the 100 runs of $2024 \mathrm{~mm}$ (rising to $2209 \mathrm{~mm}$ for the $75^{\text {th }}$ percentile). Although there is little variability between median AAR across the scenarios and timeslices, the range of results in excess of $2000 \mathrm{~mm}$ indicates considerable variability between the 100 runs as shown in Figure 3. Annual potential evapotranspiration (ETp) shows increasing variability and significant increases within the scenarios with, for example, the minimum annual average ETp of $461 \mathrm{~mm}$ within the 100 runs in the 2050 's low scenario being greater than the median value of $448 \mathrm{~mm}$ for the baseline.

[Figure 3 about here]

Average monthly temperatures changes are similar throughout the year with temperatures being cumulatively higher under each of the time periods. There is little change in winter (DJF) ETp, but progressive increases with time and emissions scenario in summer (JJA) ETp and lesser increases in spring (MAM) and autumn (SON) (Figure 4). There is a clear trend of increasing seasonality in precipitation, with increases in the winter and reductions during the summer months. The $25^{\text {th }}$ percentile monthly precipitation for the medium emissions scenario in the 2080's shows December and August to have an increase of $35 \mathrm{~mm}(+16 \%)$ and a decrease of $49 \mathrm{~mm}(-45 \%)$, respectively, in comparison to the baseline.

[Figure 4 about here]

\section{Hydrologically Effective Rainfall}

\section{Baseline}

The baseline (1961-90) estimate of average annual HER in the catchment by WaSim is $1328 \mathrm{~mm} /$ year. This is higher than the average annual HER of 1071mm (1971-2000) given by the UK Meteorological Office Rainfall and Evaporation Calculation System 
(MORECS, v2.0; Hough \& Jones, 1997) for the surrounding $40 \mathrm{~km} \times 40 \mathrm{~km}$ grid square, and by an estimate of average annual HER of $1255 \mathrm{~mm}$ derived from monthly naturalised river flow (1935-1977) for the Gauging Station 55006 below the Caban Coch Reservoir (Marsh \& Hannaford, 2008). It is considered that the WaSim estimate is acceptable, given the (1) different time periods over which the three values have been calculated, (2) input data averaging over the much larger MORECS grid square (1600 $\mathrm{km}^{2}$ in comparison to the $184 \mathrm{~km}^{2}$ for the gauging station/catchment) which results in it having a lower average altitude, a different soil type and average annual rainfall in excess of $200 \mathrm{~mm}$ lower than that of the hydrological catchment and (3) the inherent uncertainties in estimating the naturalised flows within a long-term impounded catchment.

\section{Future annual HER}

As a generalisation, the WaSim results show that there is a slight flattening and broadening of the distribution of annual HER with increasing emissions and with time, indicating increasing likelihood of very dry and very wet years. The effect of this on the uncertainty of a given annual HER range can be investigated within a single emissions scenario (i.e. across the seven timeslices) or at a single timeslice (i.e. across the three emissions scenarios). For example, the "certain" likelihood of a given annual HER occurring within the Medium emissions scenario represents the lowest likelihood of that annual HER occurring across the 100 simulations within any of the seven timeslices; whilst the $100^{\text {th }}$ percentile likelihood represents the highest likelihood of that annual HER occurring across the 100 simulations within any of the seven timeslices. Figure 5 shows the likelihood of a given annual HER range within a single (Medium) emissions scenario across all of the timeslices, and also across all of the emissions scenarios (Low, Medium and High) within a single timeslice (2070-99). Across the emissions scenario, the uncertainty in the likelihood of a given range of annual HER (as given by the range about the median likelihood) are up to $20 \%$ of the median likelihood around the centre of the annual HER distribution, but become greater and can exceed $50 \%$ within the outer parts of the distribution 
[Figure 5 about here]

\section{Future monthly and seasonal HER}

The changes in average monthly HER for the medium emissions scenario (Figure 6) show a similar pattern to that observed for precipitation (Figure 4) but with greatest reductions occurring one to two months later than precipitation due to the need to replenish larger soil moisture deficits arising from the increased evapotranspiration. Average monthly HER for summer (JJA) and winter (DJF) for the 2020's, 2050's and 2080 's for the low emissions scenario are shown in Figure 7. Average monthly summer HER under each of the time series shows a less than $10 \%$ chance of being above baseline HER. In winter the probability of HER being above baseline HER in the 2020's is $50 \%$, with the 2050 's suggesting it is very likely to be above baseline HER (92\%) and the 2080 's suggesting it is almost certain (100\%).

[Figure 6 about here]

[Figure 7 about here]

\section{Frequency of Droughts}

Although information on annual and monthly changes in HER is of value, a major concern of water resource planners is the frequency and persistence of droughts. 'Very Wet', 'Wet', 'Normal', 'Dry' and 'Very Dry' years have been classified according to percentile ranges of baseline annual HER. A future Very Dry year will have annual HER in the bottom $5^{\text {th }}$ percentile of the baseline period; a Dry year will have annual HER between the $5^{\text {th }}-20^{\text {th }}$ percentiles of the baseline; a Normal between the $25^{\text {th }}-75^{\text {th }}$; a Wet year between the $75^{\text {th }}-95^{\text {th }}$ and a Very Wet year between the $95^{\text {th }}$ to Maximum annual HER. The distribution of the different HER years within each of 100 equally probable runs under the Medium emissions scenarios in the 2020's and 2050's is shown in Figure $\mathbf{8}$, ordered by increasing frequency of Very Dry years. The number of Very Dry years varies significantly within the different runs for both timeslices, from between 10 years to 0 . 
From the 3000 modelled years for each emissions-timeslice combination, the probability of Very Wet years does not change significantly but the probability of Very Dry years increases with time and emissions by up to around 7\% (Table 2).

[Figure 8 about here]

A one year drought will be buffered by the reservoir storage but persistent or repetitive years of drought will increase stress on the environment and may affect the resilience of water supplies. To provide a preliminary assessment of the effect of the increasing frequency of droughts on reservoir storage, a simple monthly reservoir water balance of inflows (as given by the monthly HER) and outflows (taken as the combined sum of river compensation flows of $1.5 \mathrm{~m}^{3} / \mathrm{s}[\mathrm{CEH}, 2011]$ and transfer volumes of $340 \mathrm{Ml} / \mathrm{d}$, representing the average transferred to Birmingham in a drier summer [Severn Trent Water Ltd, 2008]) was conducted, allowing for a maximum storage capacity of $99,107 \mathrm{Ml}$ and a dead water level of $6 \%$ full (Severn Trent Water Ltd, 2010). From the 100 simulations for each emissions-timeslice combination, the number of consecutive years in which simulated reservoir storage fell below 35\%, which represents the lowest monthly Drought Warning trigger level, was identified. Figure 9 shows the results for each of the 30 years timeslices for the Medium emissions scenario compared to 100 baseline simulations. Although the reservoir water levels are simulated to re-fill each winter, indicating that the drought length is less than the 18-month critical period of the reservoirs, there is a general trend of increasing frequency and length of consecutive years in which summer reservoir storage reaches concerning levels.

[Figure 9 about here]

\section{Discussion}


This study has highlighted the variability in possible future climate conditions and shown that although Average Annual Rainfall (AAR) is likely to increase, annual Hydrologically Effective Rainfall (HER) is likely to decrease, resulting in reduced water availability. The impacts of climate change appear more sensitive to the time period than the emissions scenario with the 2080's showing greater variability in weather variables than the 2020's (Figure 4). The seasonal effects of climate change upon HER are significant and there is a very low probability (6\%) that HER will be above baseline conditions in summer months (JJA) of the 2080's for the low emissions scenario but a certain probability (100\%) that HER will be above baseline conditions in winter months (DJF) as shown in Figure 7. This preliminary study suggests that changes in seasonal distribution of HER coupled with increased frequency of very dry years may threaten the reliability and resilience of water supplies, necessitating water supply companies to respond to ensure the reliability of water supplies to their customers.

\section{Supply}

Historical droughts such as in 1937 and 1976 led water companies in the UK to review their storage capacity, and new schemes were constructed enabling them to supply water during the 1995/96 drought (Subak, 2000). Management procedures have also been introduced to ensure reliability of water resources, such as Drought Plans which trigger responses such as hosepipe bans or the implementation of drought permits to vary levels of abstraction.

The critical drought period from which the Elan valley reservoirs would go from full to empty without spilling is 18 months (STW, 2009), which enables current demands to be sustained whilst maintaining target levels of headroom. It is likely that the reservoirs' capacity will be able to buffer the pressures from climate change throughout the current 25 year water planning cycle, given the findings of this study and the estimated reduction in Severn Trent Water's (STW) deployable output by around $6.5 \%$ by 2025 due to climate change (Crookall \& Bradford, 2000). However, the 
longer term shifts in monthly ETp and precipitation (Figure 4) are expected to result in the increased frequency of very dry years by around 7\% (Table 2) and increasing seasonality of reservoir inflows as suggested by the HER results(Figure 6). The preliminary reservoir water storage results presented suggest that there will be increasing frequency of low summer reservoir levels as a result of the increasing seasonality of inflows, although further detailed reservoir simulation modelling is needed to assess their ability to meet demands beyond the current 25 year water planning cycle.

Alternative reservoir operating policies may provide operational and cost effective ways of mitigating reservoir system performance losses but are unlikely to work in isolation. Increasing the Elan reservoir storage capacity (Sheriff et al. 1996; EA, 2006) would counteract the anticipated increased hydrological variability, as additional surplus winter HER can be captured rather than allowed to spill.

\section{Demand}

Downing et al. (2003) suggest that the direct impact of climate change on domestic water demand is expected to be insignificant by 2020 . However, the effects of changes in demographics, technology and human behaviour may have significant effects on future water demand in Birmingham. Environment Agency (2001) indicate that future domestic demand in England \& Wales may change by -28 and $+33 \%$ between 1997 and 2025 depending on the scenario assumptions. The population of Birmingham is also expected to rise from 1,028,700 in 2009 to 1,170,000 by 2028 (BCC, 2010). The effect of the additional population will aim to be offset by the UK water strategy to reduce household consumption from 150l/p/d to 130l/p/d (EA, 2009).

Given the important climate and socio-economic uncertainties in the water resource and water demand projections and the significant economic costs involved in adaptation, the response of water companies to climate change (Arnell \& Delaney, 2006) will best be addressed through integration into a wider risk based framework 
(eg. Willows \& Connell, 2003; Lindley et al. 2006) to develop suitable adaptation strategies based on win-win or low regret options. The combination of the effects of climate change on the reliability of the water resources and the potential for significant increases in water demand from the growing population centre supports a twin track approach of reducing demand and increasing supply as the best way to maintain supplies whilst improving resilience (EA, 2009; STW, 2010). Given the capacity limit of the aqueduct that transports the water supplies from the Elan valley to Birmingham of $345 \mathrm{Ml} / \mathrm{d}$, increasing supply may need to be delivered locally through (1) increased abstraction of groundwater from the Permo-Triassic sandstone aquifer underlying Birmingham, which would require additional treatment due to contamination but will help combat rising urban groundwater levels; (2) reducing leakage from around $525 \mathrm{Ml} / \mathrm{d}(2006 / 07)$ to the target economic level of leakage of $453 \mathrm{Ml} / \mathrm{d}$ by 2015 in the wider Severn Trent region (OFWAT, 2010); (3) further network integration to allow increased transfers of water around the water distribution network.

\section{Conclusions}

1. This study suggests that water resources in the Elan valley will be impacted by future climate change. The changes in seasonal distribution of HER are significant and increasing with time, with summers showing very high (>90\%) confidence that HER will be reduced from baseline levels, with winters generally above baseline. The number of very dry years is simulated to increase by around $7 \%$ from baseline leading to increasing frequency of low simulated reservoir storage levels.

2. The direct impacts of climate change on domestic water demand are expected to be much less than the effects due to changes in technology and human behaviour and the increasing population of Birmingham. The climatic changes are likely to alter the frequency of droughts and reduce the reliability of public water supply unless supplies are increased and / or demand reduced. Increasing the Elan reservoir storage capacity would counteract the anticipated increased hydrological variability, but would be 
costly, involve long lead times and potentially (if future demand increases) be constrained by the limits of the aqueduct that transports the water supplies from the Elan valley to Birmingham.

3. The twin track approach of increasing supply and reducing demand appears the best way to maintain supplies whilst improving resilience due to the anticipated increased demands and limited capacity of current infrastructure. This could be achieved through i) Increased groundwater abstraction ii) Reductions in leakage and iii) Increased water transfers.

\section{Acknowledgements}

The authors acknowledge the support and advice provided by Richard Rees (Birmingham City Council), William Groves (Environment Agency) and Marcus O'Kane (Severn Trent Water). The views expressed in this paper are those of the authors and do not necessarily represent those of Birmingham City Council, the Environment Agency or Severn Trent Water. MORECS data were provided by John Fullwood of the Met Office, Naturalised river flow and precipitation data was provided by the National River Flow Archive and the Land Cover Map 2000 data from the Centre for Ecology and Hydrology.

\section{References}

Allen, R.G., Pereira, L.S., Raes, D. and Smith, M. (1998) Crop evapotranspiration Guidelines for computing crop water requirements. FAO Irrigation and Drainage paper 56. FAO, Rome.

Arnell, N.W. and Delaney, E.K. (2006) Adapting to climate change: Public water supply in England \& Wales, Climatic Change, 78 (2-4), 227-255.

Bates, B.C., Kundzewicz, Z.W., Wu, S and Palutikof, J.P. (Eds) (2008) 2008: Climate Change and Water. Technical Paper of the Intergovernmental Panel on Climate Change, IPCC Secretariat, Geneva, Switzerland.

Birmingham City Council (2010) Birmingham's Population, available at: http://www.birmingham.gov.uk/cs/Satellite?c=Page\&childpagename=SystemAd min\%2FCFPageLayout\&cid=1223096353755\&packedargs=website\%3D4\&pagena 
me=BCC\%2FCommon\%2FWrapper\%2FCFWrapper\&rendermode=live, (accessed $10^{\text {th }}$ July 2010).

Brisson, N. (1998) An analytical solution for the estimation of the critical available soil water fraction for a single layer water balance model under growing crops, Hydrology and Earth System Sciences 2(2-3), 221-231.

Centre for Ecology \& Hydrology (2000) Land Cover Map 2000, Centre for Ecology \& Hydrology, Wallingford, UK.

Centre for Ecology \& Hydrology (2010) UK registers second lowest Jan-June rainfall in a series from 1914, available at:

http://www.ceh.ac.uk/news/news archive/2010 news item 20.html (accessed $17^{\text {th }}$ February, 2011).

Centre for Ecology \& Hydrology (2011) Gauging station information, available at http://www.ceh.ac.uk/data/nrfa/data/station.html?55032 (accessed $17^{\text {th }}$ February, 2011)

Clwyd Powys Archaeological Trust (2010a) Historic Landscape Characterisation available at: http://www.cpat.org.uk/projects/longer/histland/elan/evrese.htm (accessed $12^{\text {th }}$ May 2010).

Conservation Engineering Division (1986) Urban Hydrology for Small Watersheds. Natural Resources Conservation Service Technical Release-55, USDA, Washington DC, USA.

Crookall, D. and Bradford, W. (2000) Impact of climate change on water resources planning, Proceedings of the Institute of Civil Engineers-Civil Engineering, 138 (2), 44-48.

Doorenbos, J. and Pruitt, W.O. (1977) Crop water requirements, FAO irrigation and drainage paper 24: Part 1 - calculation of crop water requirements, FAO, Rome.

Downing, T.E, Butterfield, R.E., Edmonds, B., Knox, J.W., Moss, S., Piper, B.S. and Weatherhead, E.K. (and the CCDeW project team) (2003) Climate Change and the Demand for Water, Research Report, Stockholm Environment Institute Oxford Office, Oxford, UK.

Environment Agency (2001) Water resources for the future: A strategy for England and Wales, Environment Agency, Bristol, UK.

Environment Agency (2006) Do we need large scale water transfers to for South East England?, Environment Agency, Bristol, UK.

Environment Agency (2009) Water for people and the environment: Water resources strategy for England and Wales, Environment Agency, Bristol, UK.

Fasinmirin, J.T., Olufayo, A.A. and Oguntunde, P.G. (2008) Calibration and Validation of a soil water simulation model (WaSim) for field grown Amaranthus, International Journal of Plant Production 2 (3), 269-277.

Fowler, H.J. and Ekstrom, M. (2009) Multi-model ensemble estimates of climate change impacts on UK seasonal precipitation extremes. International Journal of Climatology 29(3), 385-416

Gedney, N., Cox, P.M., Betts, R.A., Boucher, O., Huntingford, C. and Stott, P.A. (2006) Detection of a direct carbon dioxide effect in continental river runoff records. Nature 439(7078), 835-838. 
Hess, T.M. and Counsell, C. (2000) A water balance simulation model for teaching and learning: WaSim, HR Wallingford, Wallingford, UK.

Hess T.M., Holman I.P., Rose S.C., Rosolova Z. and Parrott A. (2010). Estimating the impact of rural land management changes on catchment runoff generation in England and Wales. Hydrol Proc 24(10), 1357-1368

Holman, I.P., Tascone, D., Hess, T.M. (2009) A comparison of stochastic and deterministic downscaling methods for modelling potential groundwater recharge under climate change in East Anglia, UK: Implications for groundwater resource management, Hydrogeology Journal, 17 (7), 1629-1641.

Hough, M.N and Jones, R.J.A. (1997) The Meteorological Office rainfall and evaporation calculation system: MORECS version 2.0 an overview. Hydology and Earth Sysyem Sciences 1(2) 227-239.

IPCC (2007), Climate Change 2007: Synthesis Report, Valencia, Spain.

Jenkins G.J., Perry, M.C. and Prior M.J.O. (2009) The Climate of the United Kingdom and Recent Trends, Revised Edition - Jan 2009, Met Office Hadley Centre, Exeter.

Jones, J.A.A. (1999) Climate change and sustainable water resources: Placing the threat of global warming in perspective, Hydrological Sciences, 44 (4), 541-557.

Jones, P.D., Kilsby, C.G., Harpham, C., Glenis, V. and Burton, A. (2009) UK Climate Projections science report: Projections of future daily climate for the UK from the weather generator, University of Newcastle, UK.

Kilsby, C.G., Jones, P.D., Burton, A., Ford, A.C., Fowler, H.J., Harpham, C., James, P., Smith, A. and Wilby, R.L. (2007) A daily weather generator for use in climate change studies, Environmental Modelling and Software, 22 (12), 1705-1719.

Lindley, S.J., Handley, J.F., Theuray, N., Peet, E. and McEvoy, D. (2006) Adaptation strategies for climate change in the urban environment: Assessing climate change related risk in UK urban areas, Journal of Risk Research, 9 (5), 543-568.

Marsh, T.J. and Hannaford, J. (eds) (2008) UK Hydrometric Register, Hydrological data UK series, Centre for Ecology \& Hydrology, Wallingford, UK.

Murphy, J.M., Sexton, D.M.H., Jenkins, G.J., Boorman, P.M., Booth, B.B.B., Brown, C.C., Clark, R.T., Collins, M., Harris, G.R., Kendon, E.J., Betts, R.A., Brown, S.J., Howard, T.P., Humphrey, K.A., McCarthy, M.P., McDonald, R.E., Stephens, A., Wallace, C., Warren, R., Wilby, R. and Wood, R.A. (2009) UK Climate Projections Science Report: Climate change projections, Met Office, Hadley Centre, Exeter.

Nakicenovic, N. and Swart, R. (eds) (2000) Special report on emissions scenarios. A special report of Working Group III of the Intergovernmental Panel on Climate Change, Cambridge University Press, Cambridge, UK.

OFWAT (2010) Leakage falls by daily need of one million customers: Only Severn Trent Water fails its leakage target, available at: http://www.ofwat.gov.uk/sustainability/ waterresources/prs pn2707 leakagefalls, (accessed $10^{\text {th }}$ August 2010).

Osborn, T.J. and Hulme, M. (2002) Evidence for trends in heavy rainfall events over the UK. Phil. Trans. R. Soc. Lond. A, $\mathbf{3 6 0}$ (1796), 1313-1325

Penman, H.L. (1950) Evaporation over the British Isles, Quarterly Journal of the Royal Meteorological Society, 76 (330), 372-383. 
Richie, J.T. (1972) Model for predicting evaporation from a row crop with incomplete cover, Water Resources Research 8(5), 1204-1213.

Rudeforth, C.C., Hartnup, R., Lea, J.W., Thompson, T.R.E. and Wright, P.S. (1984) Soils and their use in Wales. Soil Survey Bulletin No 11, Lawes Agricultural Trust, Harpenden.

Sheriff, J.D.F., Lawson, J.D. and Askew, T.E.A. (1996) Strategic resource development options in England and Wales, Journal of the Chartered Institute of Water and Environmental Management, 10 (3), 160-169.

STW (2008). Water Resources Management Plan 2009 Appendix E1: Overview of the Severn Trent Water Supply system. Severn Trent Water Ltd, Birmingham, UK.

STW (2009) Severn Trent Water: Drought Plan 2009, Severn Trent Water Ltd, Birmingham, UK.

STW (2010) Severn Trent: Water Resources Management Plan: June 2010, Severn Trent Water Ltd. Birmingham, UK.

Subak, S. (2000) Climate Change Adaptation in the UK Water Industry: Managers perceptions of past variability and future scenarios, Water Resources Management, 14 (2), 137-156.

Watts, M., Goodess, C.M. and Jones, P.D. (2004) Validation of the CRU daily weather generator. BETWIX Technical Briefing Note 4, Climatic Research Unit, University of East Anglia. Available at: http://www.cru.uea.ac.uk/cru/projects/betwixt/ (accessed $20^{\text {th }}$ May 2010).

Willows, R. I. and Connell, R.K. (eds) (2003) Climate adaptation: risk uncertainty and decision making, UKCIP, Oxford.

Youngs, E. G., Leeds-Harrison, P.B. and Chapman, J.M., (1989) Modelling water-table movement in flat low-lying lands, Hydrological Processes, 3 (4), 301-315.

Word Count - Total for document -5735

Figure captions 


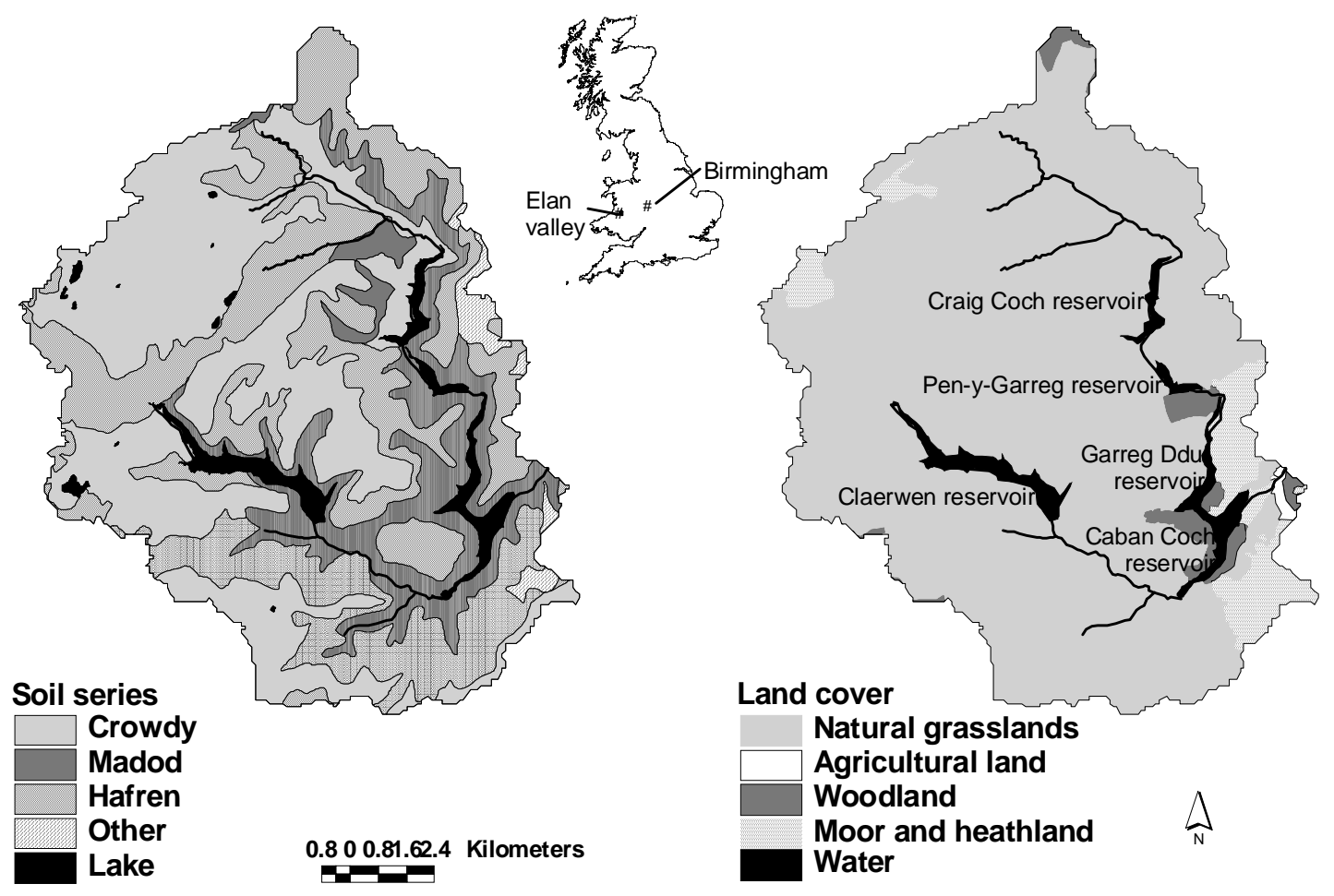

Figure 1 The Elan valley catchment and reservoirs.
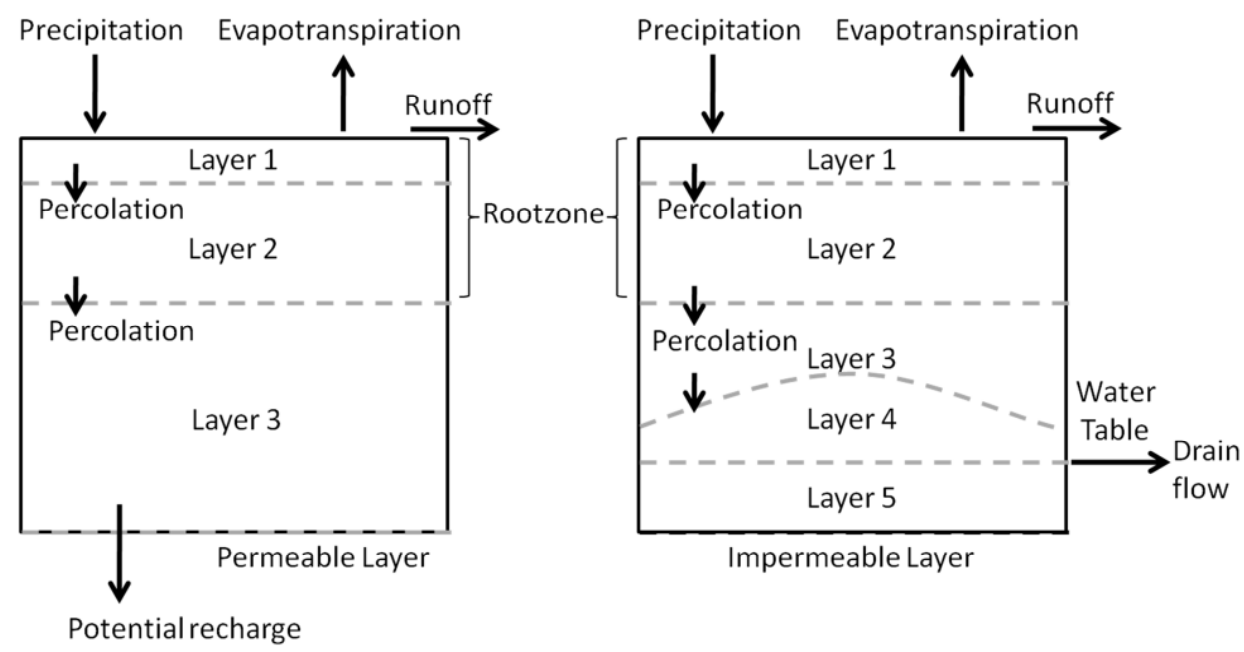

Impermeable Layer

Figure 2 Schematic of the WaSim soil water balance model for (left) freely draining and (right) low permeability soils (modified from Hess and Counsell, 2000) 


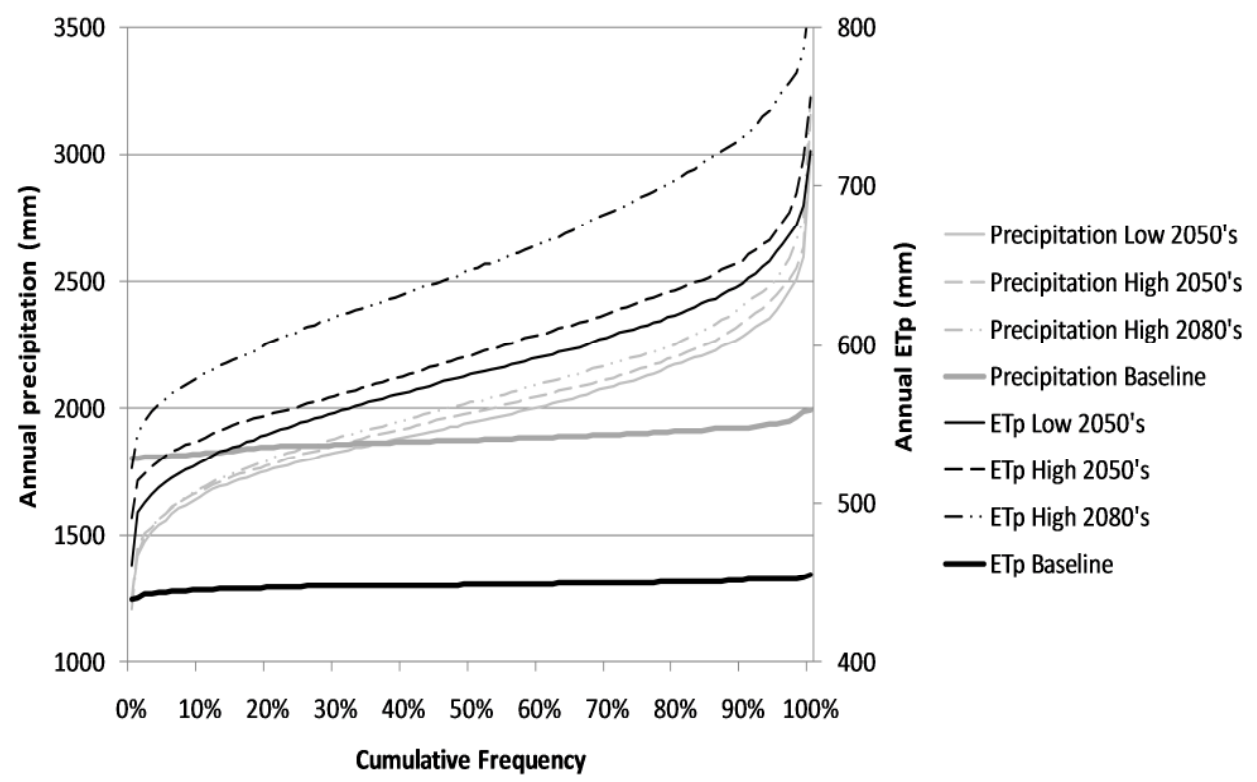

Figure 3 Cumulative frequency distribution of baseline and future Annual Average Rainfall and Evapotranspiration Potential (ETp). 

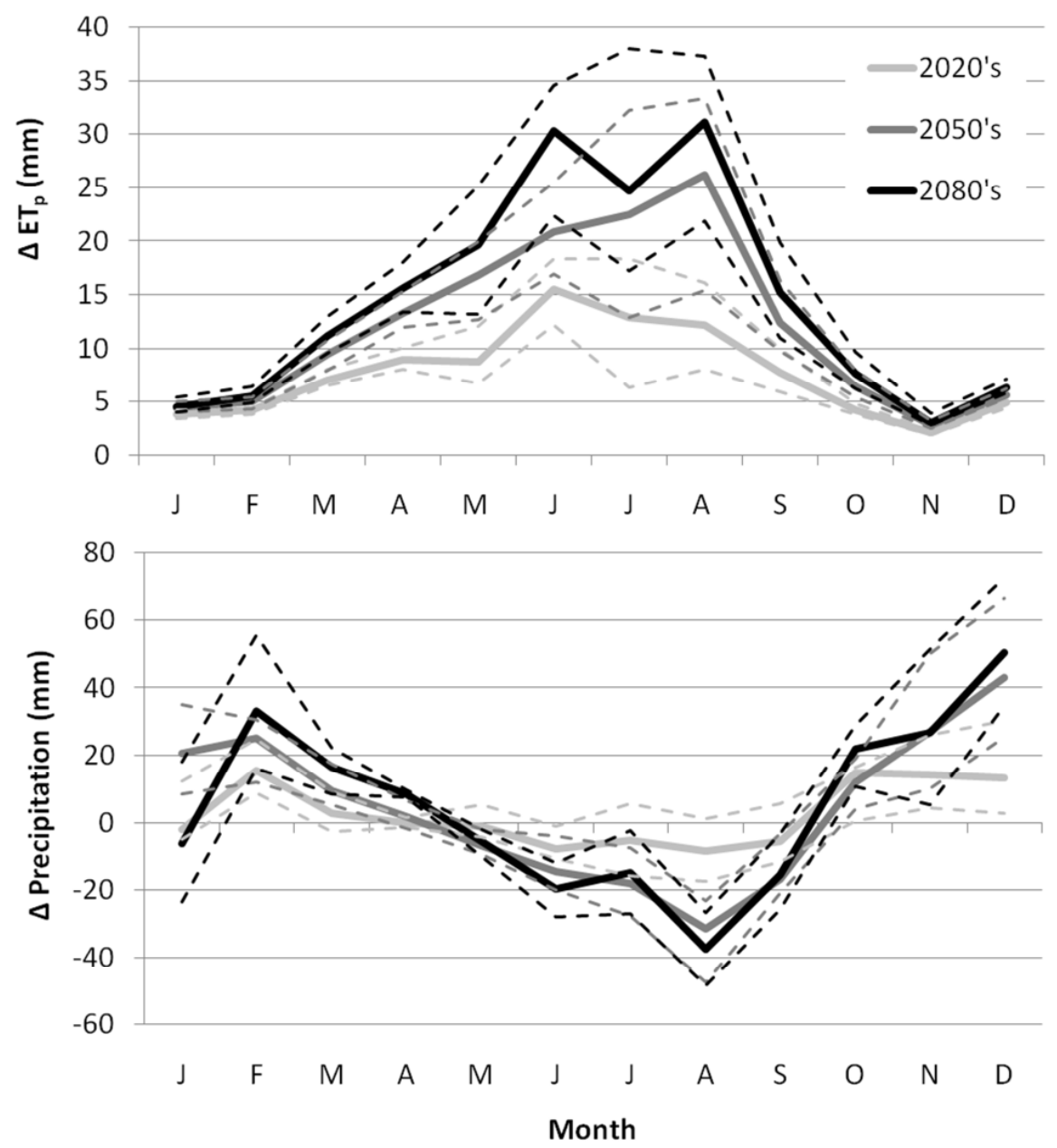

Figure 4 Long term monthly changes from baseline for (upper) Potential Evapotranspiration (ETp) and (lower) precipitation for the medium emissions scenario [median- solid line; upper and lower quartiles - dotted lines] 

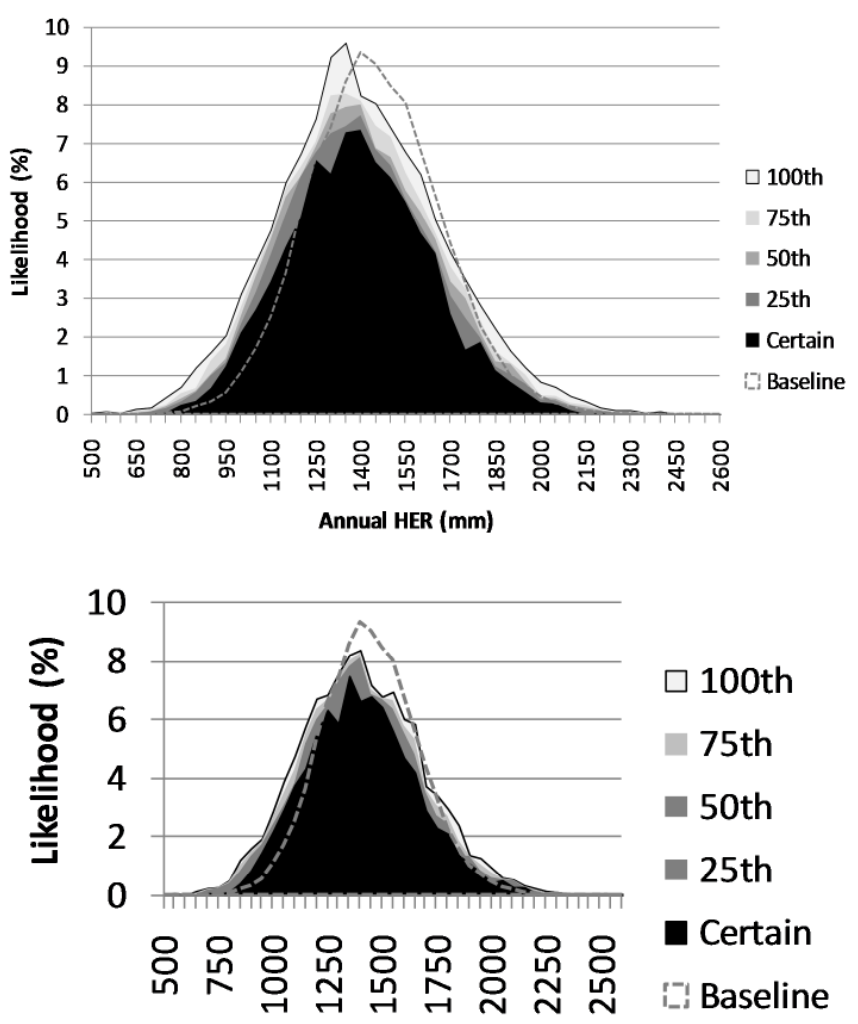

Annual HER (mm)

Figure 5 Uncertainty within annual HER due to (upper) time within the Medium emissions scenario and (lower) due to the range of emissions scenario within a single timeslice (2070-99).

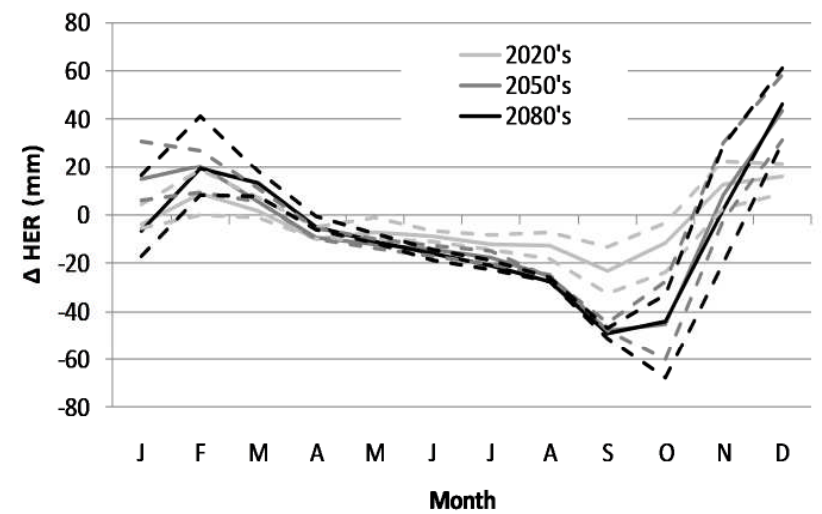

Figure 6 Long term monthly changes from baseline for Hydrologically effective Rainfall for the medium emissions scenario. [median- solid line; upper and lower quartiles - dotted lines] 

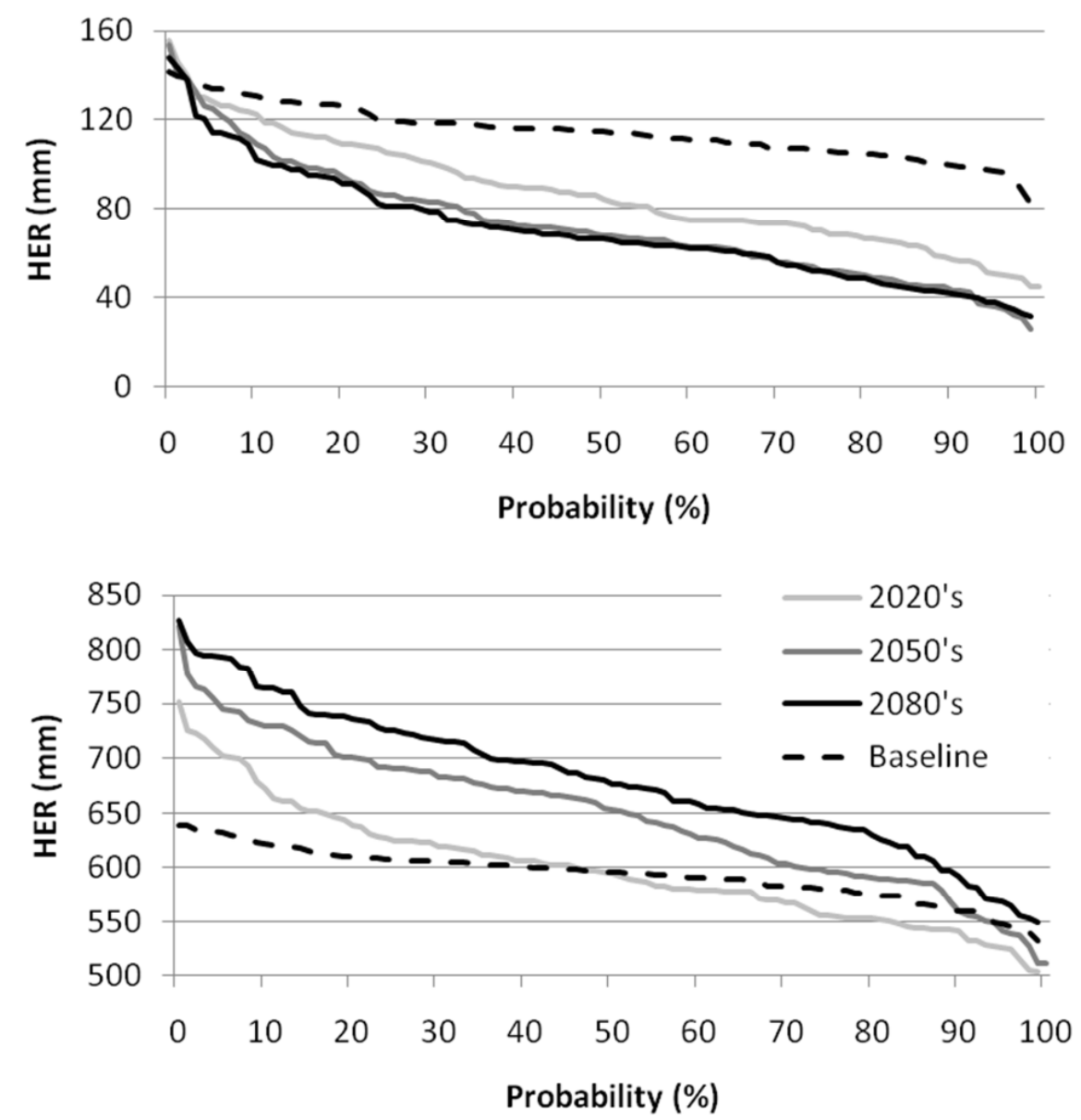

Figure 7 Average monthly Hydrologically Effective Rainfall (HER) under low emissions scenario in the 2020's, 2050's and 2080's for (upper) Summer and (lower) Winter. 

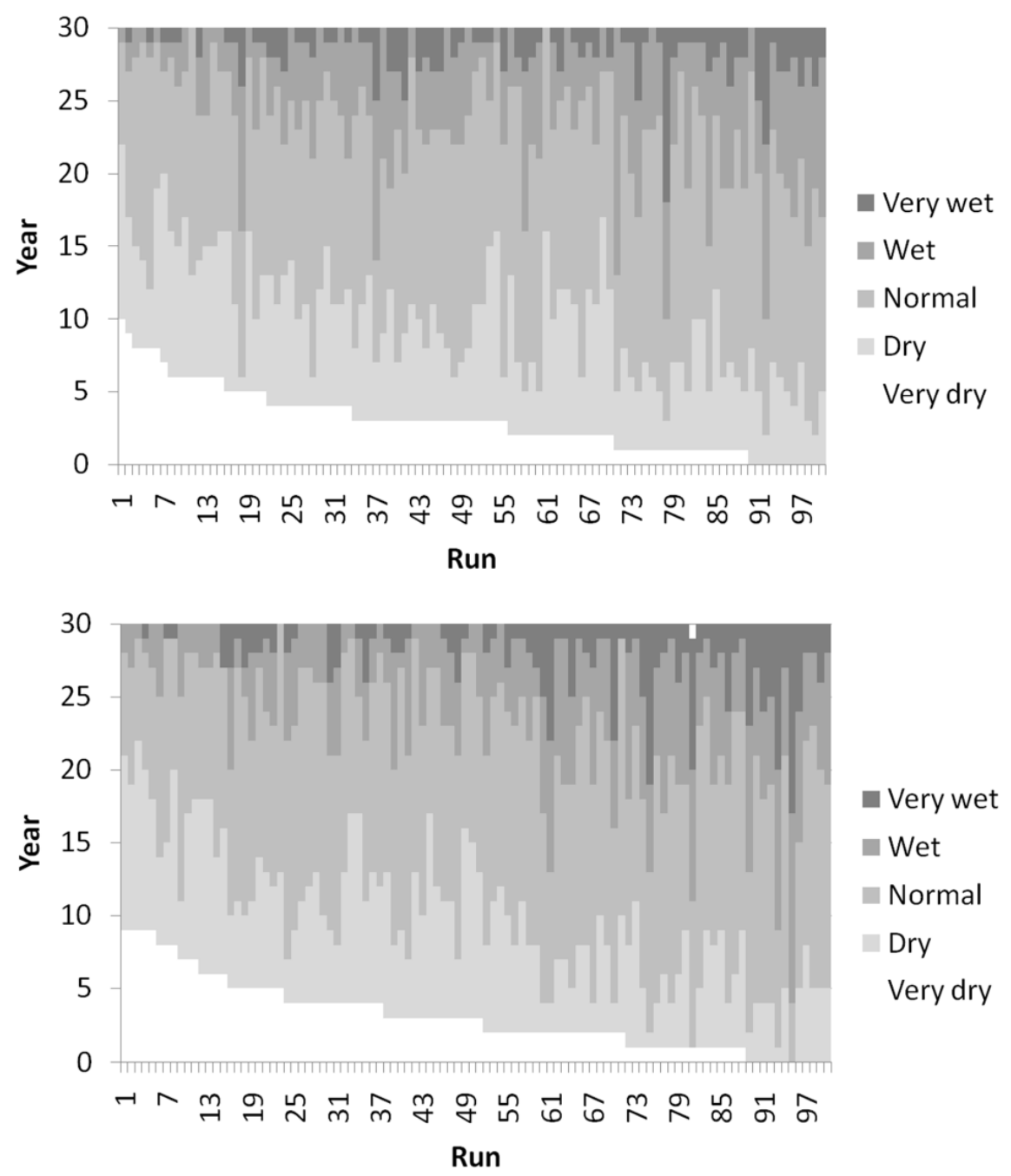

Figure 8 Frequency of very wet to very dry years in the Elan valley under medium emissions scenario for the (upper) 2020's and (lower) 2050's.

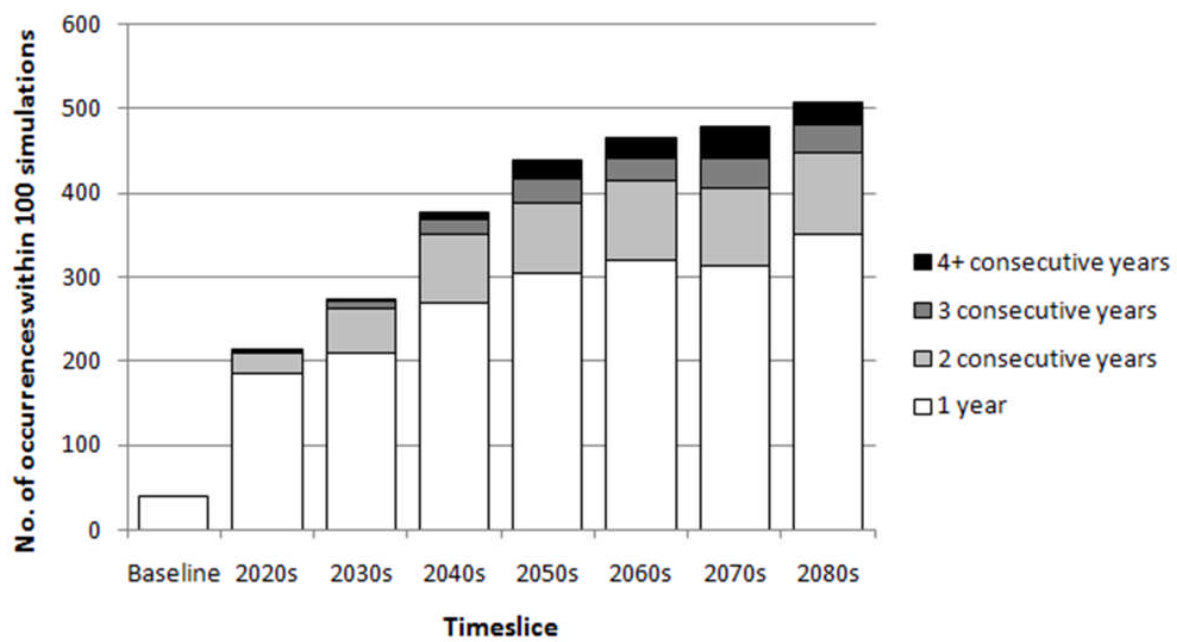

Figure 9 Number of occurrences of consecutive years in which modelled monthly reservoir 
storage falls below $35 \%$ within the 100 simulations of 30 years for the Medium emissions scenario.

Table 1 Main soil input parameters to WaSim

\begin{tabular}{l|ccc}
\hline & \multicolumn{3}{|c}{ Soil } \\
& Crowdy & Hafren & Manod \\
\hline Saturation (\%) & 88.2 & 50.5 & 58.0 \\
Field Capacity (\%) & 75.0 & 32.0 & 39.6 \\
Permanent Wilting Point (\%) & 28.2 & 12.5 & 18.7 \\
Saturated hydraulic & 1.2 & 3.1 & 2.7 \\
conductivity (m/d) & & & \\
Curve Number (AMC II) & 73 & 65 & 65 \\
\hline
\end{tabular}

Table 2 Probability (\%) of different years of differing annual HER under a range of scenarios.

\begin{tabular}{|c|c|c|c|c|c|c|c|}
\hline Annual HER & Baseline & $\begin{array}{l}\text { Low } \\
2020^{\prime} s\end{array}$ & $\begin{array}{c}\text { Low } \\
2050 \text { 's }\end{array}$ & $\begin{array}{l}\text { Scenario } \\
\text { Medium } \\
2020 \text { 's }\end{array}$ & $\begin{array}{c}\text { Medium } \\
2050 \text { 's }\end{array}$ & $\begin{array}{l}\text { High } \\
2020 \text { 's }\end{array}$ & $\begin{array}{l}\text { High } \\
2050 \text { 's }\end{array}$ \\
\hline Very Dry & 5 & 11 & 12 & 10 & 12 & 11 & 10 \\
\hline Dry & 20 & 23 & 24 & 23 & 25 & 25 & 23 \\
\hline Normal & 50 & 45 & 41 & 44 & 43 & 44 & 43 \\
\hline Wet & 20 & 17 & 16 & 17 & 14 & 16 & 16 \\
\hline Very Wet & 5 & 5 & 6 & 5 & 6 & 4 & 7 \\
\hline
\end{tabular}

